\title{
Determination of glyphosate herbicide and (aminomethyl)phosphonic acid (AMPA) in water by liquid chromatography and fluorescence detection. Part II: Direct determination using pre-column derivatization with NBD-Cl
}

\author{
R. Colin ${ }^{1,2}$, E. Le Fur ${ }^{1}$, C. Charrêteur ${ }^{1 *}$, C. Dufau ${ }^{2}$, J.-J. Péron ${ }^{2}$ \\ ${ }^{1}$ Centre de Génie Industriel, Guidel-Plages, 56520 Guidel, France \\ ${ }^{2}$ Laboratoire de Biologie et Chimie Moléculaires, Université de Bretagne Sud, rue Saint-Maudé, \\ 56325 Lorient Cedex, France
}

\begin{abstract}
An analytical method was developed for the determination of glyphosate and AMPA in water. This method involves derivatization in situ with NBD-Cl reagent at $60{ }^{\circ} \mathrm{C}$. The quantification is performed using liquid chromatography with fluorescence detection after a separation on an amino column. The limit of quantification was estimated at $1 \mu \mathrm{g} / \mathrm{L}$ level for glyphosate and at $0.1 \mu \mathrm{g} / \mathrm{L}$ level for AMPA.
\end{abstract}

Keywords. glyphosate - AMPA - analysis - fluorescence - NBD-Cl.

\section{Introduction}

In the first part of this study [1], a method for the determination of glyphosate (i.e., N-(phosphonomethyl)glycine) and AMPA (i.e., (aminomethyl)phosphonic acid) in water was developed, using the well-known fluorogenic reagent FMOC (i.e., 9-fluorenylmethyl chloroformate).

The ability of FMOC to react in water with both compounds to give fluorogenic products permitted to use the very sensitive fluorimetric detector to reach the $0.1 \mu \mathrm{g} / \mathrm{L}$ level of quantification. But one of the main problems when using such detector is the presence in certain matrix of impurities. To avoid this, we can make supplementation or modify the analytical conditions.

In the second part of the study, we attempted to develop a confirmation method and focus our efforts on amino function derivatization with fluorogenic reagents. Among them $[2,3,4]$, the non fluorescent 4-chloro-7-nitrobenzofurazan [4] (i.e., NBD-Cl) was tested. This reaction has already been proposed by Cochrane et al. [5] for the derivatization of primary and secondary amino group for amino acids. NBD$\mathrm{Cl}$, introduced in 1968 , reacts with primary and secondary amines to produce fluorescent derivatives; it also reacts with hydroxyl and thiol groups but its higher reactivity toward amino groups is effective for selective derivatization. Furthermore these adducts absorb and emit at shorter wavelengths and are less fluorescent than amine derivatives.
$\mathrm{NBD}-\mathrm{Cl}$ is extensively used as derivatization reagent for chromatographic analysis of amino acids and other low molecular weight amines. Unlike $o$-phthalaldehyde and fluorescamine, it reacts with secondary amines and it is therefore able of derivatization with secondary amino acids $[2,3,4]$. The aromatic nucleophilic substitution of glyphosate with $\mathrm{NBD}-\mathrm{Cl}$ is presented in figure 1.

The aim of this second part was to evaluate the ability of $\mathrm{NBD}-\mathrm{Cl}$ to react in water with the non selective herbicide glyphosate and its degradation product AMPA at traces level. An optimisation of derivatization and separation conditions have been made. In the conclusion, we have compared both methods in terms of specificity and sensitivity.

\section{Experimental part}

\section{Chemicals}

Glyphosate and AMPA in water $(10 \mathrm{ng} / \mu \mathrm{L})$ were supplied from Dr Ehrenstorfer (Germany). NBD-Cl (4-chloro-7nitrobenzofurazan $99 \%$ ) and glyphosate (N-(phosphonomethyl)-glycine $97 \%$ ) powders were purchased from Fluka (France). Acetonitrile (ACN), ethanol and diethyl ether, HPLC grade, were purchased from Carlo Erba (France).

*Correspondence and reprints

Received July 6, 2000; revised September 12, 2000; accepted September 19, 2000. 
<smiles>O=C(O)CNCP(=O)(O)O</smiles><smiles>O=[N+]([O-])c1ccc(Cl)c2nonc12</smiles>

Figure 1. Aromatic nucleophilic substitution of glyphosate (1) with NBD-Cl (2)

Analytical-reagent grade potassium dihydrogenophosphate, dipotassium hydrogenophosphate, disodium tetraborate decahydrate, chlorhydric acid, sodium hydroxide, phosphoric acid, were purchased from Carlo Erba (France).

Purified water, obtained from the Aqualyse System (Purite France), was used to prepare stock standard solutions of glyphosate and AMPA.

\section{Instrumentation}

HPLC system: the LC-fluorescence system consisted of a Varian model 9012 LC gradient pump equipped with a $100 \mu \mathrm{L}$ loop and a Jasco FP-1520 spectrofluorometer set at $490 \mathrm{~nm}$ (excitation) and $550 \mathrm{~nm}$ (emission).

Recording of chromatograms and measurements of peak areas were performed with a Varian-LC-Star acquisition station.

The C-18 column Pinnacle ODS, $5 \mu \mathrm{m}, 250 \times 4.6 \mathrm{~mm}$ ID, was supplied from Restek (France); the amino column Nucleosil $\mathrm{NH}_{2}, 5 \mu \mathrm{m}, 250 \times 3 \mathrm{~mm}$ ID, was supplied from Macherey-Nagel (France).

NMR spectra have been recorded in $\mathrm{D}_{2} \mathrm{O}$ at the "Service Commun de RMN-RPE" of "Université de Bretagne Occidentale" (Brest, France) on spectrometers: AC 300 Bruker, AMX3 400 Bruker, DRX avance 500 Bruker.

The chemical shifts are reported in ppm with external reference to $85 \% \mathrm{H}_{3} \mathrm{PO}_{4}$ in $\mathrm{D}_{2} \mathrm{O}$ for ${ }^{31} \mathrm{P} \mathrm{NMR}$ and with external reference to TSP for ${ }^{1} \mathrm{H}$ and ${ }^{13} \mathrm{C}$ NMR.

\section{Synthesis of pure (reference) glyphosate-NBD derivative}

A solution of $708 \mathrm{mg}$ (3.55 mmoles) of NBD-Cl in ethanol (45 mL) was added to a solution of $600 \mathrm{mg}$ (3.55 mmoles) of glyphosate in $\mathrm{NaOH} 0.5 \mathrm{~N}(14.2 \mathrm{~mL})$. The reaction mixture was heated $\left(50{ }^{\circ} \mathrm{C}\right)$ and maintained close to $\mathrm{pH} 8.0$ with $\mathrm{NaOH} 0.5 \mathrm{~N}$ during $3.5 \mathrm{~h}$ of stirring. The ethanol was evaporated under vacuum and the mixture was washed with ethyl acetate. The aqueous layer was acidified with $0.5 \mathrm{~N} \mathrm{HCl}$ to pH 1.5 and evaporated to dryness. Acetone (or acetonitrile) was added to the residue and the suspension was filtrated. The solution was dried over $\mathrm{Na}_{2} \mathrm{SO}_{4}$ and evaporated to dryness. A yield of $85 \%$ was found for the isolated derivative (orange and hygroscopic powder).

${ }^{31} \mathrm{P}$ NMR $\left(\mathrm{D}_{2} \mathrm{O}\right): 14.9$

${ }^{1} \mathrm{H}$ NMR $\left(\mathrm{D}_{2} \mathrm{O}\right): 4.4\left(\mathrm{~d},{ }^{2} \mathrm{~J}_{\mathrm{H}-\mathrm{P}}=12 \mathrm{~Hz}, 2 \mathrm{H}\right) ; 5.3(2 \mathrm{H})$; $6.8\left(\mathrm{~d},{ }^{3} \mathrm{~J}_{\mathrm{H}-\mathrm{H}}=9 \mathrm{~Hz}, 1 \mathrm{H}\right) ; 8.9\left(\mathrm{~d},{ }^{3} \mathrm{~J}_{\mathrm{H}-\mathrm{H}}=9 \mathrm{~Hz}, 1 \mathrm{H}\right)$

${ }^{13} \mathrm{C}$ NMR $\left(\mathrm{D}_{2} \mathrm{O}\right): 54.5\left(\mathrm{~d},{ }^{1} \mathrm{~J} \mathrm{C}-\mathrm{P}=144 \mathrm{~Hz}\right) ; 58.9$; $107.2 ; 124.5 ; 140.0 ; 147.2 ; 147.8 ; 149.2 ; 174.8$.

\section{Water sample preparation}

$125 \mu \mathrm{L}$ of tetraborate buffer $\left(\mathrm{Na}_{2} \mathrm{~B}_{4} \mathrm{O}_{7}, 10 \mathrm{H}_{2} \mathrm{O} 0.125 \mathrm{M}\right)$ adjusted at $\mathrm{pH} 9.25$, and $250 \mu \mathrm{L}$ of NBD-Cl solution at $4 \mathrm{~g} / \mathrm{L}$ in ethanol are added to $750 \mu \mathrm{L}$ of water sample.

After $1 \mathrm{~h}$ of reaction at $60^{\circ} \mathrm{C}$ the mixture is cooled and then $100 \mu \mathrm{L}$ of $\mathrm{HCl} 0.5 \mathrm{~N}$ are added to adjust the mixture at about $\mathrm{pH} 2$.

In these conditions, the total volume of the reactive mixture is $1225 \mu \mathrm{L}$.

\section{Water sample analysis}

Protocol 1: this protocol is associated with reverse phase chromatography on a C-18 column. The mobile phase required for the separation is a buffer $\mathrm{KH}_{2} \mathrm{PO}_{4}, 0.025 \mathrm{M}$, $\mathrm{pH} 3$; ACN (90/10) (v/v). The flow is $1 \mathrm{~mL} / \mathrm{min}$ and the chromatographic injection requires a $100 \mu \mathrm{L}$ loop.

Protocol 2: the chromatographic analysis is performed on an amino column. The mobile phase required for the separation is a buffer $\mathrm{K}_{2} \mathrm{HPO}_{4}, 0.03 \mathrm{M}, \mathrm{pH} 3 ; \mathrm{ACN}(50 / 50)(\mathrm{v} / \mathrm{v})$. The flow is $0.42 \mathrm{~mL} / \mathrm{min}$ and the chromatographic injection requires a $100 \mu \mathrm{L}$ loop.

\section{Results and discussion}

The pure glyphosate-NBD derivative has first permitted to optimise the conditions of detection by scanning the emission spectrum at an excitation wavelength set up from 300 to $600 \mathrm{~nm}$ by step of $25 \mathrm{~nm}$. The fluorescence intensity is maximal at $550 \mathrm{~nm}$ for an excitation wavelength set up at $490 \mathrm{~nm}$, in a phosphate buffer at $\mathrm{pH} 3$ and acetonitrile solution (see protocol 1).

The use of the pure glyphosate-NBD derivative has allowed us to establish the best conditions of elution and to 
optimise the derivatization reaction in situ. The molar mass ratio of glyphosate-NBD derivative and glyphosate compound is $332 / 169$. So the reaction yield can be determined by comparing the area of the chromatographic peak obtained with the pure glyphosate-NBD derivative to the area obtained with the derivatization in situ. The response factor, used to compare the yield, is expressed by peak area per ng of glyphosate injected (a.u./ng).

During the optimisation steps, the reference was a solution of pure glyphosate-NBD in water at $136 \mu \mathrm{g} / \mathrm{L}$ corresponding to $69.2 \mu \mathrm{g} / \mathrm{L}$ of glyphosate concentration. The mean response factor obtained for the synthetic derivative is $2.35 \times 10^{6}$ a.u./ng of glyphosate.

\section{Optimisation of the derivatization in water}

A C-18 column is first used because it gives a low retention time for glyphosate-NBD and have a good stability. In this way several tests have been performed to optimise the derivatization conditions of glyphosate in water (protocol 1). The influence of $\mathrm{pH}, \mathrm{NBD}-\mathrm{Cl}$ concentration, and derivatization temperature were studied separately.

The glyphosate optimal reactive form for the nucleophilic aromatic substitution involves an alkaline reactive mixture. The response is multiplied seven times when the $\mathrm{pH}$ goes from 8 to 9.75 . The response swiftly leads to a limit beyond this value. At the end of the reaction the mixture has to be acidified at $\mathrm{pH} 2$ to avoid the production of secondary compounds.

The yield of the reaction strongly increases with the reagent concentration. This concentration is optimum at $4 \mathrm{~g} / \mathrm{L}$ in ethanol. Beyond $4 \mathrm{~g} / \mathrm{L}$, the yield slowly increases and the reagent $\mathrm{NBD}-\mathrm{Cl}$ precipitates in the reactive mixture.
The reaction is too low at room temperature. The rate of the reaction increases between 25 and $60{ }^{\circ} \mathrm{C}$ but the quantity of derivative doesn't increase any more beyond this temperature. At $60{ }^{\circ} \mathrm{C}$ the time of reaction was set up at $1 \mathrm{~h}$.

Finally, we have optimised the borate buffer concentration. A good result is obtained at $\mathrm{pH} 9.75$ after $1 \mathrm{~h}$ of derivatization with a concentration of $0.025 \mathrm{M}$. A yield close to $100 \%$ is also obtained with a more concentrated buffer (0.125 M) at pH 9.25 (see Fig. 2).

The final conditions are listed in the experimental part (see water sample preparation) and adopted for the following experiments.

At this time, three observations must be done: the retention time of the glyphosate derivative is $6 \mathrm{~min}$ and no interfering signal is detected before this time. Moreover the reagent NBD-Cl doesn't give a fluorescent signal when it is not conjugated with another molecule. However, an important peak is present after $15 \mathrm{~min}$, probably due to the presence of NBD-OH form issue to the hydrolysis of NBD-Cl.

The mobile phase has to be held at $\mathrm{pH} 3$ to obtain a gaussian chromatographic peak.

The preliminary tests on $\mathrm{C}$-18 column have also permitted to check the stability of the derivative in water. When the mixture is not analysed rapidly enough after the acidification, some additional chromatographic peaks appear. Two hypotheses are presented: first the derivative decomposes itself, secondly the reactive mixture gives some non-polar compounds. Thus the reactive mixture has to be protected from light. In this way, the derivative can be kept two days without decomposition until the chromatographic analysis.

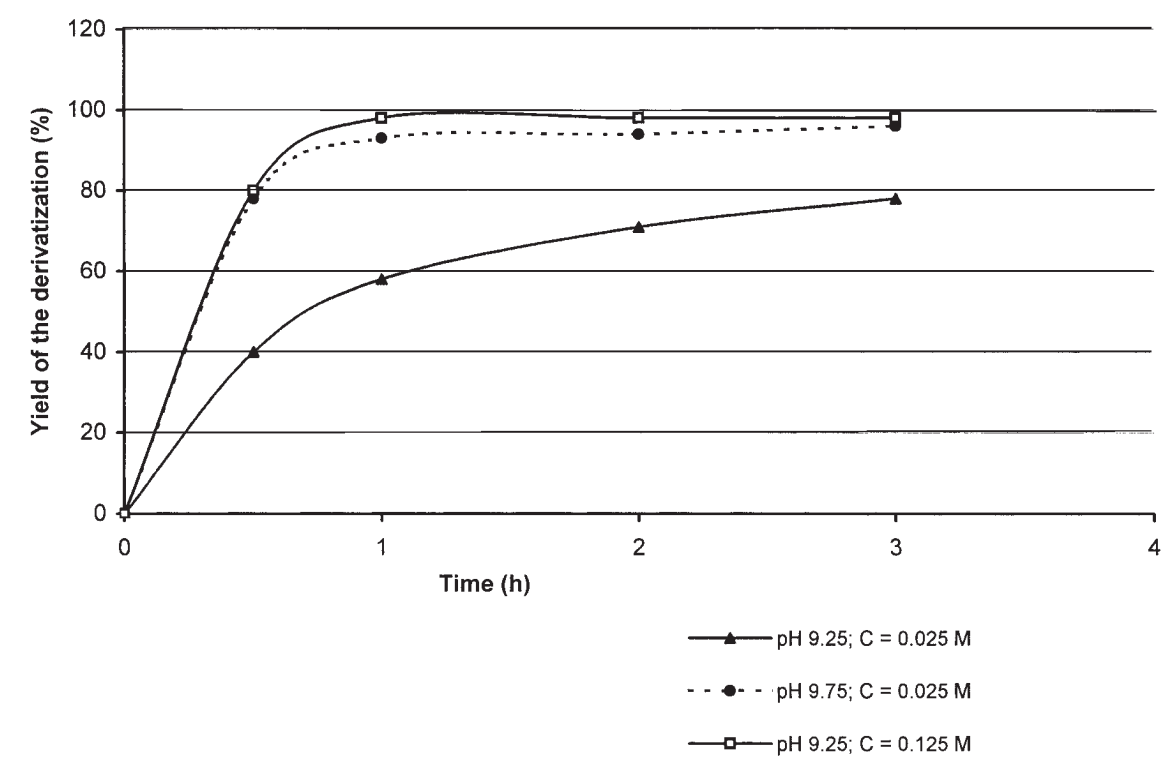

Figure 2. Optimisation of the borate buffer concentration and $\mathrm{pH}$. 


\section{Optimisation of the chromatographic separation}

The reverse phase chromatography is not a good solution to analyse the glyphosate derivative. It is too much polar to be analysed on a C-18 column so that the retention time is too low even with a strong proportion of aqueous phase in the mobile phase. The interferences present in raw waters compounds can't be separated, because of the poor selectivity of the column. That's why we made the choice of an amino column as used in part I [1].

\section{Glyphosate-NBD derivative}

In a first time, we have tested the mobile phase and especially the buffer composition and the proportion of the aqueous phase in the mobile phase. For these tests the synthetic derivative is analysed at the concentration of $136 \mu \mathrm{g} / \mathrm{L}$ corresponding to glyphosate at $113 \mu \mathrm{g} / \mathrm{L}$ in a water sample, in the derivatization conditions.

The $\mathrm{KH}_{2} \mathrm{PO}_{4}$ buffer $0.025 \mathrm{M}$ is first used as regard to the experiments performed on the $\mathrm{C}-18$ column (protocol 1), but the proportions in the mobile phase are modified (buffer; $\operatorname{ACN}(50 / 50)(\mathrm{v} / \mathrm{v}))$. In these conditions, the derivative is not eluted. It shows that a decrease of the buffer concentration in the aqueous phase leads to an increase of the retention time. Besides, an increase of the aqueous phase proportion in the mobile phase also leads to an increase of the retention time. For example, the chromatographic peak is recorded at $32 \mathrm{~min}$ when the mobile phase is $\mathrm{KH}_{2} \mathrm{PO}_{4}$, $0.05 \mathrm{M}, \mathrm{pH} 3$; ACN (60/40) (v/v).

Thus, we have to increase the concentration of buffer $\mathrm{KH}_{2} \mathrm{PO}_{4}$ beyond $0.05 \mathrm{M}$ to decrease the retention time of the derivative until a suitable value. However, damages to the column were observed by precipitation of buffer salts when using $\mathrm{KH}_{2} \mathrm{PO}_{4}$ at higher concentrations than $0.05 \mathrm{M}$.

The buffer $\mathrm{K}_{2} \mathrm{HPO}_{4}$ avoids these drawbacks because it is more soluble and its ionic strength is more important than $\mathrm{KH}_{2} \mathrm{PO}_{4}$. In this way no precipitation is observed and the retention time of the glyphosate derivative is recorded at 9 min using the following conditions: $\mathrm{K}_{2} \mathrm{HPO}_{4}, 0.05 \mathrm{M}, \mathrm{pH} 3$; $\operatorname{ACN}(50 / 50)(\mathrm{v} / \mathrm{v})$.

This too low retention time is not very suitable that's why the buffer $\mathrm{K}_{2} \mathrm{HPO}_{4} 0.03 \mathrm{M}$ is finally adopted to obtain the peak at 20 minutes (protocol 2).

\section{Glyphosate in water}

The derivatization in purified water (blank sample) shows the apparition of peaks between 6-8 min and a more significant interference observed at the beginning of the chromatogram, probably due to the NBD-OH form.

The following tests are carried out to compare the chromatograms obtained after the derivatization in situ to the ones obtained by direct injections of synthetic glyphosateNBD derivative. These tests are performed by using purified water samples spiked with glyphosate $(100 \mu \mathrm{g} / \mathrm{L})$, and other samples spiked in the same time with a part of glyphosate
$(100 \mu \mathrm{g} / \mathrm{L})$ and another part of synthetic glyphosate derivative (gly-NBD synth. $136 \mu \mathrm{g} / \mathrm{L}$ ) (see Tab. I).

The mean response factor obtained for these spiked water samples $\left(2.24 \times 10^{6}\right.$ a.u./ng $)$ is close to the response obtained for the synthetic glyphosate derivative $\left(2.35 \times 10^{6}\right.$ a.u./ng $)$. Moreover the relative standard deviation (RSD) determined for the response factor is about $6.2 \%$.

These tests prove that the derivatization in situ is efficient in the required conditions.

\section{AMPA in water}

In the same conditions of derivatization and elution, glyphosate and AMPA are analysed in spiked purified waters.

The retention time for AMPA is $9 \mathrm{~min}$ (and $20 \mathrm{~min}$ for glyphosate). Its response factor calculated as described previously is about $20 \times 10^{6}$ a.u./ng. However, the too low retention time for AMPA, near interfering signals, is a limiting factor to obtain a good quality for the signal.

Two ways have been tried to improve the quality of the signal:

- Modification of the mobile phase composition to increase the retention time of AMPA.

- Cleaning up the reactive mixture to decrease the intensity of the interfering signals.

When the proportion of the aqueous phase is higher, the retention time of AMPA increases, but much more slowly than glyphosate. In the same way the decrease of the ionic strength of the aqueous phase increases the retention time of AMPA much more slowly than glyphosate. So we don't have enough freedom to modify the mobile phase. Finally the mobile phase $\mathrm{K}_{2} \mathrm{HPO}_{4}, 0.03 \mathrm{M}, \mathrm{pH} 3$; $\mathrm{ACN}(50 / 50)$ (v/v) was kept.

The cleaning of the reactive mixture is performed after the derivatization and the addition of $\mathrm{HCl} 0.5 \mathrm{~N}$ (see Tab. II and chromatogram presented in figure 4). An equivalent volume of diethylic ether is added to the reactive mixture, then decantation for $10 \mathrm{~min}$ is necessary after stirring for $2 \mathrm{~min}$.

The cleaning with diethylic ether perceptibly decreases the intensity of the massive signal observed at the beginning of the chromatogram and also the intensity of the peaks situated between 6-8 min. So, this washing step can be exploited for the determination of both AMPA and glyphosate in raw waters.

\section{Comparison FMOC/NBD-Cl}

By calculating the slopes obtained from the calibration curves of glyphosate and AMPA derivatized with FMOC (slopes for glyphosate and AMPA are respectively $1 \times 10^{6}$ and $2.4 \times 10^{6}$; see part I, table V [I]) and NBD-Cl (slopes for glyphosate and AMPA are respectively $9.2 \times 10^{4}$ and $1.1 \times 10^{6}$; see part II, figures $3 \mathrm{~A}$ and $3 \mathrm{~B}$ ), we can compare 
Table I. Glyphosate analysis on purified water samples spiked with glyphosate and synthetic glyphosate derivative; response factor determination. Chromatographic conditions, see protocol 2 in experimental part; sample preparation, see water sample preparation in experimental part.

\begin{tabular}{|c|c|c|c|}
\hline $\begin{array}{l}\text { Composition of } \\
\text { water sample }\end{array}$ & $\begin{array}{c}\text { Quantity of } \\
\text { glyphosate injected (ng) }\end{array}$ & $\begin{array}{l}\text { Peak area } \\
\text { (area unit) }\end{array}$ & $\begin{array}{l}\text { Response factor } \\
\left(\text { a.u. } \times 10^{6} / \mathrm{ng}\right)\end{array}$ \\
\hline $750 \mu \mathrm{L}$ purified water & 0 & 0 & 0 \\
\hline $\begin{array}{l}500 \mu \mathrm{L} \text { glyphosate }(100 \mu \mathrm{g} / \mathrm{L}) \\
250 \mu \mathrm{L} \text { purified water }\end{array}$ & 4.1 & 9496798 & 2.32 \\
\hline $\begin{array}{l}250 \mu \mathrm{L} \text { glyphosate }(100 \mu \mathrm{g} / \mathrm{L}) \\
500 \mu \mathrm{L} \text { purified water }\end{array}$ & 2.0 & 4368762 & 2.18 \\
\hline $\begin{array}{l}500 \mu \mathrm{L} \text { gly-NBD synth. } \\
250 \mu \mathrm{L} \text { glyphosate }(100 \mu \mathrm{G} / \mathrm{L})\end{array}$ & 4.8 & 11712630 & 2.44 \\
\hline $\begin{array}{l}500 \mu \mathrm{L} \text { gly-NBD synth. } \\
250 \mu \mathrm{L} \text { glyphosate }(100 \mu \mathrm{G} / \mathrm{L})\end{array}$ & 4.8 & 10281073 & 2.14 \\
\hline $\begin{array}{l}250 \mu \mathrm{L} \text { gly-NBD synth. } \\
200 \mu \mathrm{L} \text { glyphosate }(100 \mu \mathrm{g} / \mathrm{L}) \\
300 \mu \mathrm{L} \text { purified water }\end{array}$ & 3.0 & 6865327 & 2.29 \\
\hline $\begin{array}{l}250 \mu \mathrm{L} \text { gly-NBD synth. } \\
500 \mu \mathrm{L} \text { glyphosate }(100 \mu \mathrm{g} / \mathrm{L})\end{array}$ & 5.5 & 13294186 & 2.42 \\
\hline $\begin{array}{l}250 \mu \mathrm{L} \text { gly-NBD synth. } \\
250 \mu \mathrm{L} \text { glyphosate }(100 \mu \mathrm{g} / \mathrm{L}) \\
250 \mu \mathrm{L} \text { purified water }\end{array}$ & 3.4 & 7549309 & 2.22 \\
\hline $\begin{array}{l}250 \mu \mathrm{L} \text { gly-NBD synth. } \\
125 \mu \mathrm{L} \text { glyphosate }(100 \mu \mathrm{g} / \mathrm{L}) \\
375 \mu \mathrm{L} \text { purified water }\end{array}$ & 2.4 & 4833609 & 2.01 \\
\hline $\begin{array}{l}250 \mu \mathrm{L} \text { gly-NBD synth. } \\
125 \mu \mathrm{L} \text { glyphosate }(100 \mu \mathrm{g} / \mathrm{L}) \\
375 \mu \mathrm{L} \text { purified water }\end{array}$ & 2.4 & 5150874 & 2.15 \\
\hline & & $\begin{array}{l}\text { Mean: } \\
\text { RSD: }\end{array}$ & $\begin{array}{r}2.24 \\
6.2 \%\end{array}$ \\
\hline
\end{tabular}

Table II. Analysis of glyphosate and AMPA with and without clean up of the reactive mixture with diethylic ether. Chromatographic conditions, see protocol 2 in experimental part; sample preparation, see water sample preparation in experimental part.

\begin{tabular}{|c|c|c|c|c|c|}
\hline $\begin{array}{l}\text { Concentration of } \\
\text { glyphosate } \\
(\mu g / L)\end{array}$ & Clean up & $\begin{array}{c}\text { Glyphosate response } \\
\text { factor } \\
\left(\text { a.u. } \times 10^{6} \mathrm{lng}\right)\end{array}$ & $\begin{array}{c}\text { Concentration of } \\
A M P A \\
(\mu g / L)\end{array}$ & Clean up & $\begin{array}{c}\text { AMPA response factor } \\
\left(\text { a.u. } \times 10^{6} / n g\right)\end{array}$ \\
\hline 67 & $\begin{array}{c}\text { yes } \\
\text { no }\end{array}$ & $\begin{array}{l}2.33 \\
2.32\end{array}$ & 33 & $\begin{array}{c}\text { yes } \\
\text { no }\end{array}$ & $\begin{array}{l}25.70 \\
20.03\end{array}$ \\
\hline 33 & $\begin{array}{c}\text { yes } \\
\text { no }\end{array}$ & $\begin{array}{l}2.24 \\
2.18\end{array}$ & 3.3 & $\begin{array}{c}\text { yes } \\
\text { no }\end{array}$ & $\begin{array}{l}20.61 \\
19.02\end{array}$ \\
\hline
\end{tabular}

the ratio obtained for the responses of glyphosate and AMPA with both methods.

In this way the ratio response glyphosate-FMOC to response glyphosate-NBD-Cl is close to 10 ; the ratio response AMPA-FMOC to response AMPA-NBD-Cl is close to 2.5 .
That means it will be not possible to reach, for glyphosate, the level of quantification at $0.1 \mu \mathrm{g} / \mathrm{L}$ by direct determination. However it is possible, for glyphosate, to reach the level of quantification at $1 \mu \mathrm{g} / \mathrm{L}$.

For AMPA, the level of $0.1 \mu \mathrm{g} / \mathrm{L}$ can be approached if there is no interfering signal at the beginning of the chromatogram. 


\section{Original articles}

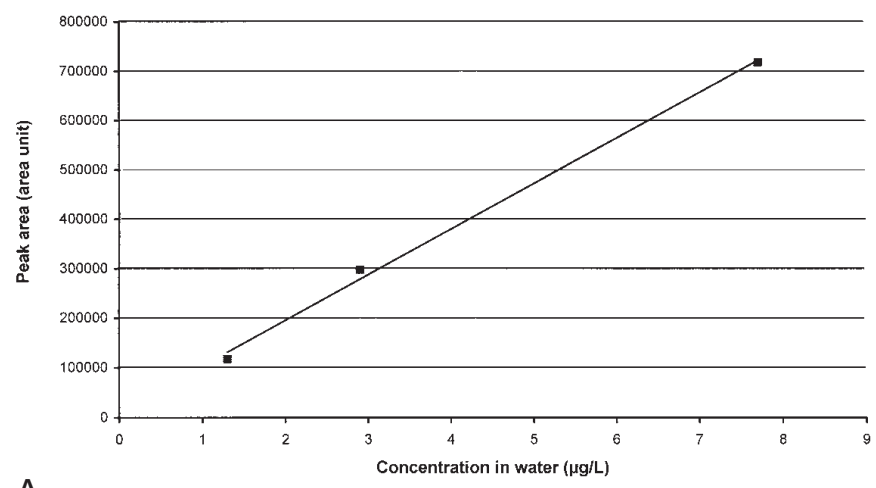

A

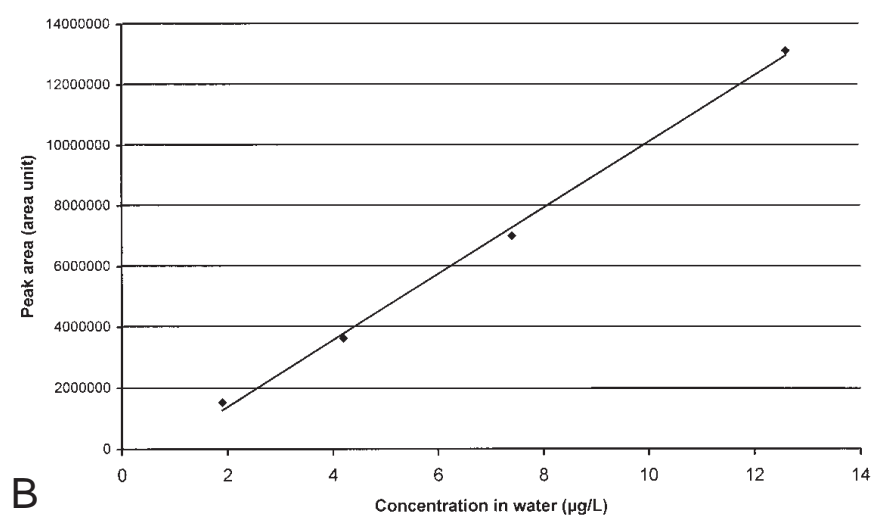

Figure 3. A. Glyphosate calibration curve in purified water. B. AMPA calibration curve in purified water. Chromatographic conditions, see protocol 2 in experimental part. Sample preparation, see water sample preparation in experimental part.

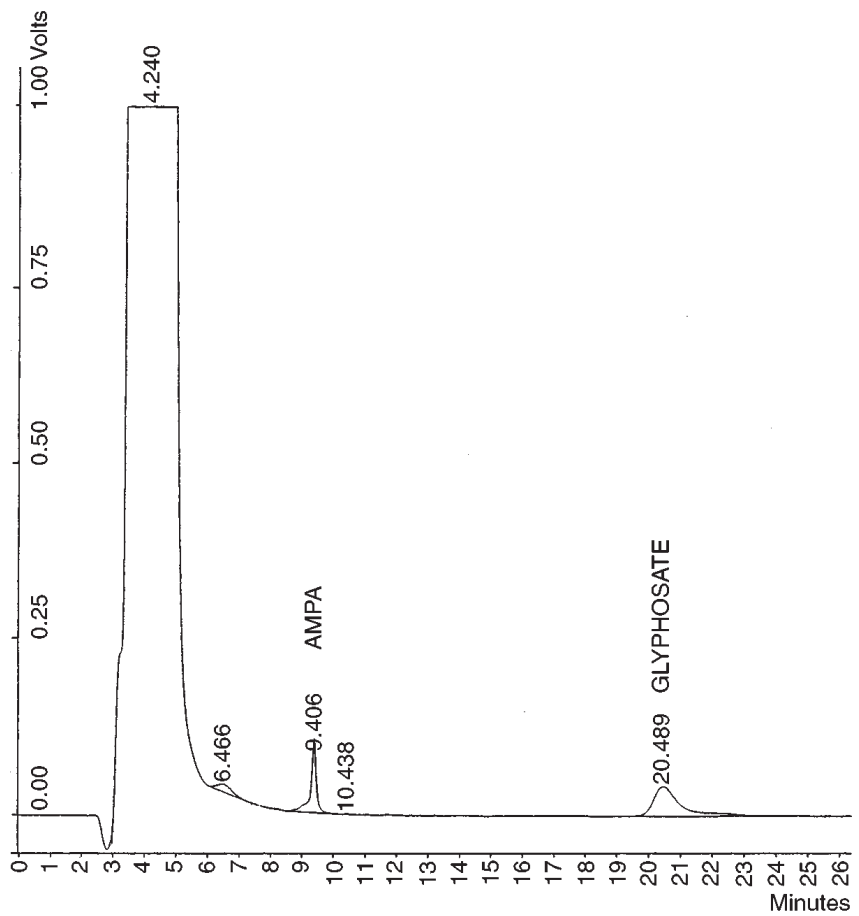

Figure 4. Chromatogram of glyphosate $17 \mu \mathrm{g} / \mathrm{L}$ and AMPA 0.8 $\mu \mathrm{g} / \mathrm{L}$, prepared in purified water, after clean up with ether. Chromatographic conditions, see protocol 2 in experimental part; sample preparation, see water sample preparation in experimental part and optimisation of the chromatographic separation in results and discussion.

\section{Conclusion}

This study shows that the method using derivatization with FMOC, to analyse glyphosate and AMPA directly in water, gives better results than the one using NBD-Cl. So the validation of this last method is not continued.

The use of pre-concentration could be tested to reach the level of quantification at $0.1 \mu \mathrm{g} / \mathrm{L}$, but at the present time, we rather like searching other derivatization reagents.

\section{REFERENCES}

1 Le Fur, E.; Colin, R.; Charrêteur, C.; Dufau, C.; Péron, J.-J. Analusis 1999, 28, 813-818.

2. Junichi, G. In Detection Oriented Derivatization Techniques in Liquid Chromatography, Lingeman, H.; Underberg, W.J.M. Ed. Chromatographic Science Series 48, New York, 1990, Chapter 9, pp 323-358 (and references therein).

3. Haugland, R.P. Handbook of Fluorescent Probes and Research Chemicals; Molecular Probes, Leiden, The Netherlands: Europe BV, 1996, Chapter 1.8, pp 39-45 (and references therein).

4. Yamaguchi, M.; Ishida, J. In Modern Derivatization Methods for Separation Sciences; Toshimasa Toyo'oka Ed, Chichester, England: John Wiley \& Sons Ltd., 1999, Chapter 3, pp 99-165 (and references therein).

5. Cochrane, W.P.; Cohen, H.; Greenhalgh, R.; Lanouette, M. Abstracts of the $5^{\text {th }}$ International Congress of Pesticide Chemistry (IUPAC), VII, C-11, 1982. 